\title{
Workshop summary: "Floods, state, dams and dykes in modern times: Ecological and socio-economic transformations of the rural world"
}

\section{Bostenaru Dan and D. Gheorghe}

Faculty of Geography, University of Bucharest, Bd. Kogalniceanu 36-46, Bucharest, Romania

Correspondence to: M. Bostenaru Dan (maria.bostenaru-dan@alumni.uni-karlsruhe.de)

Received: 13 July 2015 - Revised: 7 September 2015 - Accepted: 20 September 2015 - Published: 1 October 2015

\section{Introduction}

The workshop here reviewed took place from 18 and 20 June 2015 at the New Europe College in Bucharest, Romania. It was organised by the Francisc I. Rainer Institute of Anthropology of Bucharest, by the New Europe College - Institute for Advanced Study, and the Center of Risk Studies of the Faculty of Geography, University of Bucharest, represented by Ştefan Dorondel, Stelu Şerban and Iuliana Armaş.

\section{Overview of the scientific communications}

The workshop featured two keynote speakers: James C. Scott from Yale University, USA, who talked about the personality of rivers and how they get to the sea; and Sue Tapsell, from Middlesex University, London, who talked about participatory approaches to flood protection in the UK. Overall, the workshop talks encompassed cases from the entire world. Both keynote speakers were researchers, but they were also actively involved in management, either with the World Wildlife Fund (WWF hereafter) or with other organisations. Of special interest was the talk given by David Blake, who explained the way in which participation in hydraulic projects is seen in Thailand. The WWF speaker, Cristian Tetelea, was from Romania and approached topics of ecological biodiversity conservation at the Danube, an issue that could be experienced first-hand by the workshop participants during the workshop excursion.

In the first keynote, James Scott discussed flood events and flood protection measures, paying attention to rivers in the USA and the way they get to the lake or the sea. Each river has its own personality in this approach, and requires specific ad hoc approaches. Other speakers discussed the same subject with specific examples: Michael Cernea described relocation issues in Bangladesh as a consequence of floods, which is also a current issue in Romania, as the talk presented by Cristina Posner showed. Nowacki and Wunderlich, from the University of Frankfurt am Main, Germany, instead considered ancient flood events and how these could be recognised in palaeo-archaeological investigations. Special attention was given to participatory approaches, and to both industrialised and developed countries in eastern and western Europe. Of special interest was the explanation about how these approaches could be used in water infrastructure previously managed by totalitarian regimes.

Another topic discussed was the public participation during the construction of hydropower mega-infrastructures. Examples included not only Thailand but also eastern European countries (Ukraine, Estonia and Albania) where the political system allowed for the non-participatory implementation of hydraulic infrastructures. The exploration of cross-country contrasting approaches allowed for an interesting comparison between industrialised and developing countries, and showed a way forward into today's view on rivers, which have to be kept closer to their natural state, as mentioned in the keynote lecture. The presentation of the Ukrainian case was compared to the Canadian approach, which was particularly helpful given that a large amount of the energy consumed in Canada comes from hydraulic renewable energies. The presentation of the Albanian case benefitted from the comparison with the approach of Germany, a country where public participation is well anchored in legislation. Finally, the Swiss contribution commented on hydraulic projects in Mexico.

An incorrect approach to flood protection through the excessive use of structural mitigation measures, like building 
dams or straightening the course of the river, can cause disasters and floods. Valentin Nikolov showed the effects and causes of dam failure in the municipalities of Tsar Kaloyan and Harmanli in Bulgaria, while Töhötöm Árpád Szabó focused on the role of politics in disasters today, after the fall of the curtain, regarding dikes in the Romanian Carpathians, an area inhabited by different ethnic groups (Hungarians and Roma). Ethnic conflicts can have effects on the disastrous management of the river, as presented by sociologist Oana Mateescu, who explained how the change of the ecosystem (by removing the green infrastructure of forests) led to an increased vulnerability to floods. We also learned about the role of mountain ecosystems in fast mountain rivers, as fast streaming can be stopped by mountain forests. Many of the communications above dealt with rivers in the final part of their flow, including the Danube, when the floodplain forms a particular habitat, but mountain rivers are instead integrated into the habitat around. This might be a topic for further discussion. The role of micro-hydropower as opposed to megainfrastructures was discussed, as was the importance of the flora and fauna in river mountains and how they are affected by power infrastructures, a topic of particular interest for the WWF.

The second keynote speaker, Sue Tapsell, dealt with the relationship between vulnerable population groups and ecology. In the UK, women seem to be more sensitive to flood protection and are more involved in land management and protection. Cristina Posner showed how women possessed a special expertise in dealing with disasters, usually being more preoccupied with the household. Women were also more vulnerable in Muslim countries, as a presentation by Ali Nobil Ahmad showed, while analysing the 2010 disaster in Punjab, Pakistan. Both clothing and education contributed to this, so it is a combined vulnerability determined by gender, religion and ethnicity. The talk by Miljkovic and colleagues from Serbia approached the participative dimension in the post-socialist area. In this case, flood influenced soil properties that are important for health and well-being, since they determine environmental pollutants. The situation is different in a country with tradition in participation; perception and communication of risks are an example of how to proceed, as presented by Gutscher from Zurich, Switzerland.

In the case of eastern Europe, the post-totalitarian state was seen to be critically important. In fact, the workshop was one of the outcomes of the project "Taming the Postsocialist Nature: Floods, Local Strategies and National Policies along The Lower Danube" (http://www.politicalecology.ro/). The goal of the project was to understand multi-criteria decisionmaking for disaster management, which involves the participation of both experts and the affected communities. The project itself was presented in the talk by Dorondel and Ivan, as well as by Posner on behalf of colleagues. The lessons learned were relatively new for eastern Europe, which was dominated by totalitarian regimes in 1968 , when these theories began to develop in western Europe. However, in case of many of the out-of-Europe examples, the political dimension of ecological perspectives is managed similarly in postcolonial countries.

\section{The field trip to ecologically restored areas on the Bulgarian Danube shore}

The field trip consisted of a short visit to Brashlen, a recently ecologically restored area, formerly used for agriculture. The location is situated east of Ruse, along the Danube, where water levels are still carefully monitored and maintained through the connection to the Danube. Ecosystem restoration was possible by changing land use from agriculture to conservation and leisure. The previous agricultural use required drainage, resulting in strong environmental impacts. The currently managed water levels allow the growth of native hydrophilic species, which are protected by law. The use of technology for conservation was very positive, since the water levels were maintained through careful control. Finally, ecosystem restoration benefited from tourist infrastructures based on traditional values and uses, which showed that floodplains could be managed, as exemplified by the presentation by Stelu Şerban from the Institute for South-East European Studies, Bucharest, Romania, on "Communal Ecology and Natural Restoration on the Danube".

\section{Discussion}

Overall, the workshop tried to value the specific local flood culture. Local seismic culture is a spread concept, promoted, for example, by the European University Centre for Cultural Heritage in Ravello, Italy, and by numerous initiatives dealing with vernacular architecture, for example, in the centre CRAterre, Ecole Nationale Supérieur d'Architecture de Grenoble, France, and at Escola Superior Gallaecia, Vila Nova de Cerveira, Portugal. The doctoral thesis of Alina Florea at the "Ion Mincu" University of Architecture and Urbanism on emergency housing examined relocation in flood reconstruction at the Danube and beyond considering the involvement of local knowledge.

A second objective of the workshop was to reflect on the role of the floodplain in flood protection. Recent European policies promote the maintenance of the natural state of rivers, as exemplified by the works of Nicolas Triboi in Romania. Landscape planning, in general, can play a role in fighting climate change through measures to protect against flood (and drought). Hydrological works that led to the canalisation of rivers, either for better navigation or for energy generation, are questionable in contemporary Europe. A recent COST action (TU1401 "Renewable energy and landscape quality") discusses the environmental impact of such infrastructures. In Romania, the Vidraru hydropower plant was used as an example of the effect of such infrastructures 
on the floods of the river Arges in the 1950s; other examples also included dam break studies.

Participation is assimilated into the local cultures, which, thus, became more resilient to natural disasters. Participation in countries like Romania is not traditional, as it is in Germany or other western European countries. Participation can be also connected to the mentioned local knowledge if we consider it in the context of reconstruction measures, as in the doctoral thesis of Alina Florea.

While in western Europe, topics such are renewable energy and public participation have been extensively discussed in the last decade, this workshop was a welcome start for the sensibilisation of western European countries.

Thus, flood protection through planning is directly related to landscape planning. A number of projects in Germany dealt with investigating the role of landscape architects in preventing flooding through the restoration of river areas, for example, the project "Fluss, Raum, Entwerfen" (river, space, project) at the University of Hanover and the doctoral thesis of Jan Dieterle on risk landscape of the Upper Rhine. Floods and climate change are spatial-structural challenges for the landscape of the Upper Rhine.
Through this project (based on the workshop), the knowledge on flood protection through landscape intervention became part of the local communal knowledge, similar to local seismic cultures. Traditional interventions proved to be more sustainable than modern interventions. These traditional interventions involve the ecological development of river ecosystems without the need for technical intervention such as the one performed in Romania during the totalitarian regime.

Acknowledgements. The authors' views are expressed as part of the POSDRU 133391 project. The presented views are relevant also for COST action TU1401 RELY.

Edited by: D. Montesinos

Reviewed by: one anonymous referee 